\title{
DIE PROBLEMATIEK VAN MILITÊRE OPLEIDING
}

Kapt M.H. Heydenrych*

\begin{abstract}
INLEIDING
"The essential characteristics of a good army are that it be well trained and well disciplined. These two characteristics are apparent in ever unit achievement, whether in peace or in war. Discipline derives and flows from training and serves to emphasize a fundamental point essential to a philosophy of training: that training is allencompassing. Training permeates everything a military organization does" (Collins 1978: 1).
\end{abstract}

In die lig van die beëindiging van die RSA se betrokkenheid in Namibië, het daar by die SuidAfrikaanse Weermag (SAW) noodwendig 'n klemverskuiwing plaasgevind vanaf ' $n$ meer defensiewe optrede (gerugsteun deur opleiding) na ' $n$ meer opleidingsgerigte optrede met die oog op proaktiewe beveiliging van die Suid-Afrikaanse gemeenskap.

'n Weermag (soos ook die SAW) is 'n unieke organisasie hoofsaaklik vanweë die unieke aard van sy primêre funksie, naamlik die verdediging van die land wat kan lei tot die dood van mense. Dit kan geskied tydens defensiewe (dit wil sê verdedigend na aanleiding van aggressiewe optrede deur 'n aggressor) of offensiewe optrede. Geen ander soort organisasie beskik oor 'n soortgelyke primêre funksie nie (Van Dyk 1980: 71).

Militêre opleiding as deel van die voorbereiding vir bogenoemde optrede speel ' $n$ belangrike rol en dit is dan ook die taak waarmee enige weermag hoofsaaklik in vredestyd besig is, met ander woorde die vaardigheid van oorlogvoering word hoofsaaklik in vredestyd geleer. Die beginsels van, asook die strategie en taktiek van oorlogvoering word aan militêre opleidingskolleges en aan ander militêre opleidingsinrigtings gedoseer.

Hoewel die weermagopleidingsinrigtings oor dieselfde fisiese eienskappe beskik as ander tersiêre opleidingsinrigtings, naamlik lesinglokaalfasiliteite, instrukteurs/dosente, media, ensovoorts, geskied hierdie opleiding in 'n oorheersend militêre milieu - ' $n$ faktor wat ' $n$ bepaalde invloed op die opleiding uitoefen. Die an- dersheid van hierdie milieu in vergelyking met die tradisioneel-tersiêre opleidingsmilieu behoort duidelik te blyk uit die hieropvolgende bespreking van die unieke aard van die militêre milieu.

\section{DIE UNIEKE AARD VAN DIE MILITERE MILIEU}

\section{Die Kompleksiteit van ' $n$ Weermagsor- ganisasie}

Die bestuur van militêre bedrywighede in ' $n$ weermag is gewoonlik in die hande van die militêre professie - mense wat professioneel opgelei en funksioneel gespesialiseerd is in die institusionele toepassing van geweld. Militêre deskundiges is verantwoordelik vir ' $n$ verskeidenheid van administratiewe, tegnologiese, ekonomiese, diplomatieke, politieke en opvoedkundige aktiwiteite. So bestaan ' $n$ tipiese leërorganisasie in die SAW uit stafafdelings wat verantwoordelik is vir die ondersteunende funksies en vegtende eenhede bekend as die lynfunksie. Die vegtende eenhede is suiwer volgens funksionele spesialisering ingedeel in infanterie, pantser, artillerie en andere (Van Dyk 1980: 72, 77).

Hierdie kompleksiteit skep 'n milieu met 'n eiesoortige karakter.

\section{Onvoorwaardelike onderwerping van Individuele Belange}

Die mens is 'n sosiale wese wat normaalweg in 'n groep leef en funksioneer. Om in ' $n$ groep te leef vereis egter dat die individu sommige belange ondergeskik moet stel aan die belange van die groep. Hierdie reël (meestal ongeskre we) geld in die breë samelewing.

Die militêre kontrak is egter uniek in hierdie opsig. Dit vereis die algehele en feitlik onvoorwaardelike onderwerping van die belange van die individu aan die belange van die groep, selfs to in so ' $n$ mate dat daar van die individu verwag kan word om sy lewe af te lê - dus totale onderwerping (Hackett 1983: 140). 


\section{Geweld as Doelstelling}

Hoewel daar nie eksplisiet na geweld as doel gestreef word nie, word daar by implikasie van die individu in sy militêre rol verwag om geweld te pleeg en ' $n$ "professional in violence" (Janowitz 1960: 3) te wees. Dit spruit uit die aard van 'n weermag se primêre funksie, naamlik verdediging van die land wat tot die dood van mense kan lei. Die individu word onder andere opgelei in die gebruik van vernietigende wapens. Hierdie doelstelling is direk teenstrydig met wat van die individu in die samelewing verwag word, naamlik respek vir die lewe en eiendom van 'n ander. Ernstige konflik kan ontstaan tussen hierdie sterk siviele indoktrinasie teen geweld en "moord" en die weermag se doelstelling om die vyand te vernietig. Na-oorlogse studies het aan die lig gebring dat talle soldate in die voorste linies nie hulle vuurwapens afgevuur het nie. Die redes hieroor is gesoek in die moonlikheid van ' $n$ verstarrende vrees wat hulle oorweldig het of in die feit dat hulle hulself nie sover kon bring om ' $n$ lewe te neem nie selfs in oorlogstoestande. Volgens Ginzberg (1959: 102) "they understood, on an intellectual level, the need of their country to fight - which is why they did not seek classification as conscientious objectors - but they were unable in combat to pull the trigger because they were so strongly emotionally conditioned against taking human life". ' $n$ Ernstige konflik in waardes kan ' $n$ beduidende invloed uitoefen op die effektiewe funksionering van die individu in sy militêre rol.

\section{Die Verantwoordelikheid van die Individu}

Die militêre rol is egter nie alleen kompleks soos uit bogemelde aspekte blyk nie, maar dra "a share of responsibilities whose gravity is second to none - for peace or war and for the protection of nations and ideals" (Downey 1977: 19).

Volgens Ginzberg (1959: 3) kan demokrasie nie oorleef nie tensy sy burgers gehoor gee aan die oproep om die wapens op te neem as hul land in gevaar verkeer. "Meeting the performance demands of war is an obligation of every man" (Ginzberg 1959: 3).

\section{'n Hiërargie van Gesag}

Hoewel daar in elke organisasie ' $n$ hiërargie van gesag bestaan, word ' $n$ weermag en onder andere die SAW gekenmerk deur 'n goed omskryfde hiërargie van gesag. Die hiërargiese vorm van 'n militêre organisasie bestaan uit 'n aantal vlakke van bestuur wat elk oor bepaalde gesag, verantwoordelikheid en aanspreeklikheid beskik en waarin die meerdere-ondergeskikte verhouding duidelik waarneembaar is (Van Dyk 1980: 77). Hierdie eienskap is nie uniek aan die militêre milieu nie. Wat egter wel uniek is, is die feit dat elkeen van hierdie vlakke gekoppel is aan ' $n$ spesifieke rang.

Van Dyk (1980: 81) wys daarop dat hierdie rangstruktuur bydra tot onpersoonlike interpersoonlike verhoudinge in die militêre milieu aangesien dit die grondslag vorm vir 'n onpersoonlike aanspreekvorm, vir 'n voorgeskrewe wyse van groet, vir 'n duidelike voorgeskrewe kommunikasiekanaal en vir skriftelike kommunikasie slegs deur die voorgeskrewe kanale.

Afwyking van hierdie neergelegde gedragskode kan vir die individu ernstige gevolge inhou in die vorm van tugstappe.

\section{Militêre Dissipline}

Met militêre dissipline word hoofsaaklik twee oogmerke nagestreef. Eerstens is dit daarop gemik om te verseker dat die soldaat nie aan die natuurlike instink van selfbehoud toegee in die aangesig van groot gevaar nie, maar dat hy sy bevele sal uitvoer al sou dit sy dood beteken. "The object of discipline in this case is to leave no doubt in the mind of any officer or man about where his duty lies... When discipline is seen at its best it provides a buttress to support the soldier in his struggle against his own fears" (Baynes 1987: 180).

Tweedens word daar met militêre dissipline beoog om orde binne 'n weermag te handhaaf ter wille van beheer en doeltreffendheid. Dissipline kan ook verhoed dat 'n weermag sy mag misbruik en in wanorde verval.

Dissipline in die tradisioneel-rigiede vorm word duidelik omskryf in die woorde van Veldmaarskalk William Slim (Roskill 1964: 66): "Discipline ... is the sacrifice of a man's comfort, inclination, safety, even life, for others, for something greater than himself. It is the refusal to be the weak link in the chain that snaps under strain".

Hoewel daar ook die afgelope 40 jaar 'n geleidelike klemverskuiwing plaasgevind het vanaf "beheer" na "leierskap" bly militêre dissipline, met gehoorsaamheid aan hoër gesag as grondslag, 'n uitstaande kenmerk van die militêre milieu. 


\section{Militêre Etiek}

Etiek dui op die beskouing oor wat in 'n spesifieke situasie of vir ' $n$ spesifieke groep reg of verkeerd is. Die militêre professie het ' $n$ taak wat vereis dat menselewens opgeoffer word en dat menselewens doelbewus geneem kan word. Gegewe die rol van die soldaat, is dit duidelik dat ' $n$ bepaalde gedragskode en waarde-oordeel nodig is om 'n dimensie van menslikheid te verleen. Die militêre etiek vorm die kern waarvolgens die soldaat se gedrag en waarde-oordele beheer en gerig word (Hoof van die SAW: KINGSROW-verslag 1987: 46).

Etiek in die militêre professie is egter nie net nodig om etiese gedrag voor te skryf en morele chaos te voorkom nie, maar ook om die militêre organisasie daartoe in staat te stel om effektief te veg. Die nakoming van etiese beginsels is by uitstek belangrik in die geveg waar daar dikwels waarde-oordele toegepas moet word en besluite, wat die verskil tussen lewe en dood impliseer, geneem moet word. Onbetroubaarheid, dislojaliteit en gebrek aan integriteit in die gevegsituasie, kan gevegsgereedheid ernstig benadeel met verreikende gevolge (Hoof van die SAW: KINGSROW-verslag 1987: G-7).

Kwaliteite soos lojaliteit, integriteit, eerlikheid, volharding, toegewydheid, dissipline, onselfsugtigheid, geloofwaardigheid, regverdigheid, morele moed en betroubaarheid is dus nie soos in die meeste ander professies alleen moreel begeerlik nie, maar is in 'n weermagorganisasie (en ook die SAW), ter wille van militêre effektiwiteit, essensieel.

\section{Mobiliteit as 'n Lewenswyse}

Hoewel geografiese mobiliteit ' $n$ kenmerk van die moderne samelewing is, is die unieke mobiele lewenswyse van die militêre gesin ongeëwenaar deur enige ander groep. ' $n$ Aktiewe lid kan te enige tyd aangesê word om te verhuis. Hierdie mobiele lewenswyse beïnvloed dikwels die gesinsrolle en dit is veral die vrou en kinders wat geraak word. Hoewel studies deur Shaw, Duffy en Privitera (Hunter 1982: 38) aan die lig gebring het dat voorskoolse kinders nie noemenswaardig ontwrig word deur gereelde verhuising nie, is daar tog bevind dat die militêre kind (buiten die bemeestering van die normale ontwikkelingstake) addisionele spanning ervaar as gevolg van geografiese mobiliteit. Dit is egter veral die adolossent wat aanpassingsprobleme ondervind (Hunter 1982: 38).
Die militêre vrou voel dikwels nog meer bedreig deur hierdie lewenswyse as die kinders omdat sy nog meer spanning ervaar as die kind. Nuwe vriendskappe moet gesluit word. Sy moet dikwels afstand doen van haar betrekking met 'n gevolglike verlies aan voordele, salarisverhogings, senioriteit, ensovoorts. Die gesin se ekonomiese sekuriteit word soms drasties ondermyn aangesien verhuisingskostes dikwels hoër is as die verhuisingstoelaag wat die gesin ontvang. Aan die positiewe kant is die geleentheid om nuwe ervarings deelagtig te word; die gesinseenheid kan versterk word en in die meeste gevalle baat die verplaasde individu se loopbaan by die verplasing (Hunter 1982: 41).

Hierdie eienskap van die militêre milieu gee ook onvermydelik aanleiding tot tydelikheid. Nie alleen word mense voortdurend in hul werksituasies vervang deur ander nie, maar die weermag opleidingsinrigtings ervaar ook ' $n$ konstante vloei van studente wat nuwe vaardighede moet aanleer vir die eise wat aan hulle gestel word in hul nuwe werksomstandighede.

\section{Gesinskeiding}

Buiten die moontlikheid om verplaas te word, kan 'n lid van die weermag te enige tyd opgeroep word vir aktiewe diens (in Suid-Afrika was dit tot onlangs veral grensdiens) of vir 'n opleidingskursus aan ' $n$ weermagkollege. Sommige van die kursusse vereis voltydse inwoning van die lid byvoorbeeld die leër- en lugmagstafkursusse waar ' $n$ lid tot 9 maande van sy gesin geskei word. Militêre gesinskeiding, wat letterlik deel van die militêre leefwyse is, vereis dat elke lid van die gesin ' $n$ aanpassing moet maak ten opsigte van die verandering. Die afwesigheid van een ouer plaas noodgedwonge die verantwoordelikhede met gepaardgaande spanning na die oorblywende ouer, gewoonlik die vrou, oor. Volgens Hunter (1962: 13) kan hierdie rolsverandering verreikende gevolge vir die hele gesin hê: "There is a hierarchy of authority within the military system, and although the wife to some extent has the duties and privileges associated with the husband's rank, she has nonetheless been placed in a dependant status. Ironically, when the family is separated, she must immediately take over the reins and is forced into an unfamiliar and independent single-parent role. Through necessity, wives take on stereotypic masculine roles while the husbands are away. They must venture into the outside world and into the masculine realm if 
they are to maintain a functioning household. Marital problems may be caused by separations because of the inevitable changes in marital roles, which occur both from the opportunity for and the necessity to develop independence during the husband's abscence. Separations present a new concept of the wife's role, and she develops an unwillingness to shift back to her former passive, dependent role after the husband's return."

Ook die kinders word nie ongedeerd gelaat deur ' $n$ vader se voortdurende en/of langdurige afwesigheid nie en dit kan aanleiding gee tot simptome soos gesondheidsprobleme, negatiewe gedrag, swak skoolprestasie, ensovoorts.

"Recurring father absence often leads to a sense of artificiality and a chronic sense of fragmeritation in the family and an ever-present threat to family stability", aldus Rosenfeld, Rosenstein and Raab (Hunter 1982: 29).

\section{Gevaar van Dood of Besering}

Hoewel die soldaat nie noodwendig altyd in operasionele toestande moet funksioneer nie, bestaan daar altyd die moontlikheid dat hy blootgestel kan word aan omstandighede wat beserings of die dood kan veroorsaak - iets wat normaalweg vrees inboesem. Tog moet die individu in die weermag genoeg selfbeheer aan die dag lê om herhaaldelik deel te neem aan aksies wat tot die dood of verminking kan aanleiding gee.

In SA was lede van die weermag vir die afgelope paar dekades blootgestel aan ' $n$ bosoorlog aan die grens met die gepaardgaande blootstelling aan gevaar. Nie alleen hou dit spanning in vir die individu nie, maar ook vir sy hele gesin. "Missing in action", "a hostage experience", "a prisoner of war experience", "killed in action" (Hunter 1982: 58 ) is moontlikhede wat die soldaat in die gesig staar en waarmee sy gesin ook moet saamleef 'n faktor wat 'n negatiewe uitwerking op die gesinstabiliteit kan uitoefen.

\section{Die diverse Aard van Militêre Verpligtinge}

Anders as die burgerlike werknemer wat hoofsaaklik aangewend word in sy beroepspesifieke veld, word die weermaglid selde uitsluitlik aangewend in sy spesifieke beroepsrigting. Hierdie nie-beroepsverwante pligte verskil van weermagsdeel tot weermagsdeel asook tydens operasionele toestande. Wool (1968: 62) dui daarop dat die militêre beroep in dié opsig baie anders is as die siviele beroep: "the military man must devote a significant portion of his working time to duties outside his field of occupational specialization, ranging from military duties (such as guard duty) to a variety of housekeeping details. Although the nature and level of the latter duties vary by rank, they do not necessarily vary by occupational speciality or mental/educational qualifications. This practice stands in sharp contrast to general utilization patterns of trained workers in civilian employment where both economic considerations and more formal institutional constraints limit any extensive utilization of skilled personnel in unskilled duties".

\section{Militêre Lewe versus Burgerlike Lewe}

Benewens bogenoemde aspekte wat grootliks eiesoortig is aan die militêre milieu, onderskei die soldaat hom ook nog deur byvoorbeeld die dra van ' $n$ uniform en is hy deel van ' $n$ militêre kultuur met die gepaardgaande militêre tradisies.

Hackett (1983: 202) onderskei tussen die militêre lewe en burgerlike lewe op 'n treffende wyse in sy woorde: "The essential basis of the military life is the ordered application of force under an unlimited liability. It is the unlimited liability which sets the man who embraces this life somewhat apart. He will be (or should be) always a citizen. So long as he serves he will never be a civilian".

\section{INTRINSIEKE FAKTORE WAT MILITÊRE OPLEIDING IN DIE SAW BEİNVLOED}

Benewens die kompleksiteit van die militêre milieu en die diversiteit van die opleiding binne hierdie milieu wat ' $n$ bepaalde invloed op militêre opleiding as sodanig het, is daar ook ander intrinsieke faktore wat nie buite rekening gelaat kan word by die opleidingsbeplanning in die SAW nie.

\section{Die Omvang van Militêre Opleiding}

Opleiding van die volksweermag (alle volwasse mans tussen 18 en 65 jaar) is 'n omvangryke taak. Slegs die aantal Staandemaglede wat byvoorbeeld jaarliks opleiding in een of ander spesialisrigting ontvang is beduidend genoeg om die opleidingstaak te kompliseer. In 1989 was die aantal Staandemaglede wat opleiding ontvang het ongeveer 6000 . Dan is daar ook nog 
die Burgermag, Dienspligmag en Burgerlike komponent teenoor wie die SAW 'n opleidingsverantwoordelikheid het.

\section{Die Heterogeniteit van Studentegroepe}

Studentegroepe aan SAW opleidingsinrigtings is baie heterogeen van aard veral ten opsigte van vlakke van ontwikkeling en ouderdom. Instrukteurs word dikwels op een kursus met die minder en meer volwasse student gekonfronteer, en moet kan onderskei tussen die kind (voorvolwassene) en die volwassene (hetsy vroegvolwassene, hoogvolwassene of laatvolwassene) aangesien dit die didaktiese benadering in sy geheel beïnvloed. Net soos dit onversoenbaar met die aard van die kind sou wees om hom in die onderrigsituasie as volwassene te hanteer, is dit onversoenbaar met die aard van die volwassene om hom as kind te hanteer. 'n Heldere begrip van volwassenheid is dus die basis vir die bepaling van onderrigstrategieë vir volwassenes.

Die SAW is ook vanweë die multi-kulturele samestelling van die Suid-Afrikaanse bevolking in ' $n$ toenemende mate verplig om multi-kulturele opleiding aan te bied. Die SAW moet dus in sy opleiding toenemend voorsiening maak vir die verskille in agtergrond, kultuur, taal en opvoedingsvlakke van die onderskeie bevolkingsgroepe.

Benewens die kultuurverskille tussen onderskeie bevolkingsgroepe, bestaan daar ook verskeie subkulture binne die SAW. So vorm elke weermagsdeel ' $n$ eie unieke subkultuur wat opgebou is deur kollektiewe ervaring en bestaan uit elemente van onderlinge verhoudinge en eensgesindheid (Hoof van die SAW: KINGSROW-verslag 1987: F-5). Die weermagsdele se kulture spruit grootliks uit hul inherente en unieke bestuurs- en leierskapsrolle. Die Suid-Afrikaanse Leër is 'n organisasie wat met groot groepe werk. Die Suid-Afrikaanse Lugmag, daarenteen, is ' $n$ individualistiese organisasie, terwyl die Suid-Afrikaanse Vloot spangeoriënteerd is en die Geneeskundige Dienste ' $n$ weermagsdeel is wat op hoogs onafhanklike en professionele vaardighede staatmaak.

Selfs binne ' $n$ betrokke weermagsdeel kan subsubkulture voorkom, byvoorbeeld artilleriste teenoor infanteriste, vlieëniers teenoor navigators, ensovoorts (Hoof van die SAW: KINGSROW-verslag 1987: F-5).
Opleiding in die SAW geskied nie altyd net binne 'n bepaalde weermagsubkultuur nie en dikwels word daar oor die grense heen beweeg. Kursusse by byvoorbeeld Personeeldiensskool asook by die SAW Kollege vir Opvoedkundige Tegnologie, om net twee te noem, word deur lede van al vier die weermagsdele bygewoon. Met inagneming van die kultuurverskille wat tussen weermagsdele bestaan, moet derglike gesamentlike opleiding met groot omsigtigheid bedryf word en hoewel daar 'n behoefte bestaan aan die uitruiling van gedagtes op die kulturele vlak, is dit belangrik dat die eiesoortigheid van elke weermagsdeel gerespekteer word ( $\mathrm{Hoof}$ van die SAW: KINGSROW-verslag 1987: F-6).

Die implikasie wat bogenoemde heterogeniteit van studentegroepe vir die opleier inhou, behoort voor die hand liggend te wees - suksesvolle opleiding word grootliks gekompliseer.

\section{Koste verbonde aan Militêre Opleiding}

Weermagte dra in die algemeen nie by tot volksinkomste nie en veroorsaak eerder 'n dreinering van beskikbare fondse (De Munnik 1979: 37). Moderne konvensionele oorlogvoering met die gepaardgaande duur wapentuig en instandhouding van krygsmagte veroorsaak dan ook geen geringe dreinering van hierdie fondse nie. Gedurende vredestyd word ' $n$ beduidende gedeelte van hierdie fondse na opleiding gekanaliseer aangesien ' $n$ weermag in vredestyd hoofsaaklik gemoeid is met die opleiding van sy magte. Beplanners van opleiding en alle opleidingspersoneel het die taak om bronne optimaal te benut en die kostes verbonde hieraan realisties te hou.

\section{Tydigheid}

Omdat 'n oorlog nie tot die dag en datum voorspel kan word nie, is dit nodig om as voorsorgen gereedheidsmaatreël 'n nasionale strategie te skep en militêre opleiding daarvolgens te beplan. Opleidingsbeplanners moet tyd dus optimaal benut om te verseker dat alle soldate die grootste mate van vegvaardigheid opbou en in stand hou om in die kortste moontlike tyd gereed te wees (De Munnik 1979: 38).

\section{Tydelikheid}

Soos reeds genoem gee die mobiele aard van die militêre lewe onvermydelik aanleiding tot ty- 
delikheid. Die kwessie van tydelikheid is egter nie net ter sprake wanneer daar na die menslike hulpbronne verwys word nie. Die verandering in tegnologie en wapentuig en verandering in die vyand se vermoë en strategiese/taktiese doktrines noodsaak voortdurende aanpassing (De Munnik 1979: 38).

\section{Realisme}

Anders as in die meeste ander beroepe waarvoor opleiding gegee word, ontbreek realisme by die opleiding van die soldaat. Dit is nie moontlik om 'n oorlog te ontketen bloot om soldate op te lei nie. Vir die doel van militêre opleiding word oorlog egter gesimuleer om die realisme van die slagveld te voorsien. Simulasie is egter geen goedkoop en geen eenvoudige metode van opleiding nie. Hoewel die instrukteur sekere aspekte van die slagveld kan simuleer (bv slagveldgeraas) is dit veel moeiliker om aspekte soos die onmenslike spanningstoestande wat eie is aan 'n oorlog na te boots. Tog word daar van die militêre instrukteur verwag om die soldaat se spanningstoleransie so uit te bou dat hy wel spanning kan hanteer. Die feit dat hierdie opleiding in vredestyd gedoen word en die soldaat se reaksie op spanning eers in ' $n$ werklike konfliksituasie waarneembaar en meetbaar is, kompliseer die taak van die instrukteur om die soldaat sielkundig voor te berei vir oorlog (De Munnik 1979: 40).

Die instrukteur moet ook deurgaans rekening hou met 'n situasie wat tot frustrasie kan lei, naamlik opleiding vir 'n oorlogsituasie wat miskien nooit sal realiseer nie. Dit is hier waar die professionele soldaat se beroep grootliks verskil van ander beroepe - die praktiese toepassing van die teorie van oorlogvoering ontbreek waar daar vrede in ' $n$ land heers. Dit is moontlik een van die redes waarom weermagte deel het aan die Verenigde Volke se vredesmagte (soos UNTAG): dit bied ' $n$ geleentheid om praktiese ervaring op te doen.

\section{EKSTRINSIEKE FAKTORE WAT MILITÊRE OPLEIDING IN DIE SAW BEINVLOED}

\section{Eksterne Omgewing}

Die eksterne omgewing verwys na die staatkundige, ekonomiese en maatskaplike terreine waarbinne die SAW as organisasie moet funksioneer en wat ' $n$ direkte of indirekte invloed het op die eise wat daar aan opleiding gestel word.
Die SAW opleidingsisteem funksioneer dan ook nie in ' $n$ vakuum nie en is voortdurend in wisselwerking met sy omgewing.

Op staatkundige gebied moet die SAW-opleier in 'n toenemende mate bewus wees van die invloed van internasionale politiek en die staatkundige situasie op die RSA in die algemeen en die SAW in die besonder. In SA is dit veral nodig om groot sensitiwiteit aan die dag te lê by die hantering van ander bevolkingsgroepe asook lede met uiteenlopende politieke oortuiginge. Die SAW-opleier kan dan ook baie vermag in die sielkundige voorbereiding van die SAW-lede om by die veranderde en veranderende omstandighede aan te pas.

Die ekonomie van die RSA is onderhewig aan groot buitelandse sowel as binnelandse druk en word tans gekenmerk deur 'n lae ekonomiese groei, hoë inflasie, 'n lae goudprys en lae waarde van die Rand teenoor die meeste ander geldeenhede. Van owerheidsweë word die klem in 'n toenemende mate gelê op besparing en produktiwiteit. Omdat die SAW-opleidingsisteem nie in isolasie kan bestaan nie, behoort opleidingspersoneel so wetenskaplik moontlik op te tree in hul opleidingsbenadering ten einde die SAWfondse meer effektief te bestee en so besparing in die hand te werk - ' $n$ faktor wat noodwendig ' $n$ invloed sal (en reeds) uitoefen op die totale opleidingsbenadering in die SAW.

Die SAW-opleier moet dus te alle tye rekening hou met bogenoemde realiteite.

\section{Standaarde in Opleiding}

'n Baie hoër graad van vaardigheid word van die militêre spesialis verwag as van sy kollega in die burgerlike lewe omdat lewe en dood letterlik daarvan kan afhang. Hier kan gedink word aan die opleiding van plofwapenopruimingskundiges en die opleiding van valskermspringers. Slegs een foutjie kan die verskil maak tussen lewe en dood. Dit sal ook te laat wees om op die slagveld te ontdek dat die opleidingstandaarde van die soldate te laag was en hierin lê volgens De Munnik (1979: 41) die problematiek. Vegvaardigheidstandaard is baie relatief en word sterk beïnvloed deur die rol wat motivering, vrees, doelgerigtheid en spanning tydens konflik speel en skep ' $n$ dilemma vir die opleier wat moet besluit wanneer hy die vereiste standaard in vredestyd bereik het wat in oorlog sukses sal verseker. 


\section{Die Bedreiging}

"Opleiding vir oorlog is opleiding om te verseker dat soldate 'n effektiewe teenreaksie kan loods teen enige vyandige aksie. Selfs hierin is ' $n$ probleem vir die instrukteur. Inligtingsbronne moet voortdurend die aard van ' $n$ militêre bedreiging ontleed en opleidingsbeplanners voer met informasie wat vyandelike vermoëns en voornemens beskryf. Daarvoor moet dan opleidingsaanpassings gemaak word" (De Munnik 1979: 42).

Met die oog op die veranderende gebeure in SA is bogenoemde stelling veral relevant.

\section{DIE DIVERSE AARD VAN MILITÊRE OPLEIDING}

Asof bogenoemde faktore nie genoeg is om enige opleier in die SAW met ontsag te vervul vir die komplekse en omvattende opleidingsverantwoordelikheid wat voor sy deur gelê word nie, staar die realiteite van die diverse aard van militêre opleiding hom ook nog in die gesig.

In die SAW sluit opleiding ' $n$ groot verskeidenheid didaktiese vorme in (De Munnik 1977: 28, 1979: 46).

\section{Induksie, Oriëntasie en/of Basiese Opleiding}

As gevolg van die feit dat die weermag voortdurend met oningeligte en onvoorbereide personeel te doen het, moet die individu eers militêr georiënteer word vir sy rol en taak in die weermag. Met hierdie oriënteringsopleiding word nie alleen verseker dat die persoon maklik ingeskakel word in die militêre milieu nie, maar hy leer ook die basiese elemente van die professie ken en word fisies en geestelik gevorm vir die taak wat vir hom in vredestyd sowel as oorlog mag wag (De Munnik 1977: 29).

\section{Beroepsvaardigheidsopleiding}

Onder hierdie opleiding word onder andere die volgende tipes opleiding geklassifiseer:

\section{- Inposopleiding}

Hier verwys dit na die nie-formele, maar tog beplande en gestruktureerde opleiding binne die werksituasie. Inposopleiding hou direk verband met die aard van die individu se funksie en is daarop gemik om enige leemte ten opsigte van sy vermoë om sy werk te verrig, uit te skakel.

\section{- Tegniese Opleiding}

Die SAW maak gebruik van hoogs ingewikkelde toerusting en wapentuig. Om in die behoefte aan 'n tegniese mannekragvermoë te voldoen, onderneem die weermag sy eie vakleerling-opleiding om ambagsmanne en tegnici te voorsien. Die snelontwikkelende tegnologie vereis ook voortdurende heropleiding.

\section{- Professionele Opleiding}

Vanweë die groot verskeidenheid van take is die SAW ook betrokke by die opleiding van professionele personeel soos geneeshere, rekenmeesters, medici, ingenieurs, argitekte, sielkundiges, personeelpraktisyns, ensovoorts. Benewens die universiteitsopleiding wat hierdie persone ontvang, word die geleentheid geskep om internskap te voltooi waarna professionele status toegeken word. Hierdie professionele personeel moet egter hulle kennis in 'n militêre milieu toepas en ontvang om hierdie rede ook nog aanvullende militêre opleiding (De Munnik 1979: 48).

\section{- Militêre Vaardigheidsopleiding}

Uit die aard van 'n weermag se primêre funksie, is dit noodsaaklik om soldate daar te stel wat die hoogste mate van wapenbehendigheid bemeester het. In die SAW behels dit opleiding in wapenlewering vanaf gesofistikeerde wapenstelsels soos missiele, vegtersvliegtuie en slagskepe tot eenvoudige wapens soos landmyne, handgranate en bajonette. Die aanleer van vaardighede soos skiet, perdry, spoorsny, oorlewing, valskermspring, ensovoorts, wat 'n belangrike plek in militêre opleiding beklee, kan ook gekategoriseer word onder vaardigheidsopleiding (De Munnik 1978: 29; 1979: 47).

- Opleiding in Opvoedkundige Tegnologie Aan die SAW Kollege vir Opvoedkundige Tegnologie word die soldaat in die SAW opgelei om sy bestaande spesialiskennis en vaardighede deur middel van die toepassing van die beginsels van die Opvoedkundige Tegnologie aan sy studente oor te dra. Daar word van die standpunt uitgegaan dat hoewel die soldaat ' $n$ spesialis op ' $n$ bepaalde gebied mag wees, dit nie veronderstel dat hy dié kennis sinvol kan oordra nie. Die individu ontvang dus, buiten opleiding in instruksionele ontwerp, ook opleiding in die groot verskeidenheid van didaktiese vorme en die gebruik van tegnologiese hulpmiddels (De Munnik 1979: 49). 


\section{Bestuursvaardigheidsopleiding}

\section{- Algemene Bestuursopleiding} Vanweë die kompleksiteit van 'n moderne weermag word van veral senior personeel verwag om die mens, materiaal en fondse beskikbaar vir die verdedigingspoging, effektief te bestuur (De Munnik 1979: 50).

Bestuursopleiding word dan ook op die verskillende vlakke (junior-, middel- en seniorbestuursvlak) aangebied. Die verskillende vlakke is gewoonlik gekoppel aan die verskillende vlakke in die rangstruktuur.

\section{- Toesighouersopleiding}

Toesighouersopleiding vorm 'n belangrike deel van feitlik elke opleidingsprogram in die SAW omdat daar toesighouers op elke vlak benodig word om die bevel en beheer waar te neem.

\section{- Bevelsopleiding}

Hierdie opleiding is daarop gemik om die bevelvoerder van 'n militêre eenheid daartoe in staat te stel om effektiewe bevel te voer.

\section{- Stafopleiding}

Senior personeel word opgelei om as adviseurs op te tree ten opsigte van operasionele, administratiewe en logistieke beplanning en die voorbereiding en voorsiening van alle moontlike vorms van inligting wat besluitneming by bevelvoerders moontlik maak ( $\mathrm{De}$ Munnik 1977: 30).

\section{SLOTSOM}

$\mathrm{Na}$ aanleiding van bogenoemde bespreking van die problematiek van militêre opleiding kan dit tereg opgemerk word dat die opleidingspersoneel in die SAW ' $n$ haas bomenslike taak het en is daar sekerlik geen eenvoudige oplossing waarmee 'n parate weermag deur middel van opleiding daargestel kan word nie.

Die SAW het hom egter in sy opleidingsbeleid verbind tot die toepassing van Opvoedkundige Tegnologie beginsels en lewer dit dan ook ' $n$ aansienlike bydrae tot die verhoging van die gehalte van opleiding in die SAW. Hoewel daar n verskeidenheid interpretasies van die begrip Opvoedkundige Tegnologie is, handhaaf die SAW die siening dat dit 'n tegnologie van die onderrig is; dat dit veel meer as net oudiovisuele nedia omvat; dat die student sentraal staan in die onderrig/leergebeure; dat dit die implemen- tering van ' $n$ sisteembenadering is om die voordeligste verhouding tussen koste en effektiwiteit te verkry en dat 'n hegte integrasie van teorie en praktyk as vertrekpunt geneem word (Van Niekerk, 1990: 6).

Deur middel van die Opvoedkundige Tegnologie word die opleidingspersoneel in die SAW in staat gestel om die mees geskikte inhoude, metodes en media te kies ten einde die betrokke teikengroep vir hul take voor te berei. Die opleidingspersoneel word ook deur middel van die Opvoedkundige Tegnologie in staat gestel om die SAW-opleidingsisteem (wat binne die breë raamwerk van 'n eiesoortige organisasie en milieu, naamlik die SAW, funksioneer) so te bestuur dat die doel waarna gestreef word, naamlik 'n parate weermag nie slegs 'n onbereikbare ideaal is nie.

Hoewel daar ook dikwels na die soldaat op baie verskillende maniere gekyk word ("Our God and soldiers we alike adore/ev'n at the brink of danger; not before." Francis Quarles, Epigram), word daar ook onder die vaandel van die Opvoedkundige Tegnologie in die SAW gewaak teen die verontmensliking van die mens in uniform.

\footnotetext{
* Kapt (mev) M.H. Heydenrych, BA (Unisa), DTO (Unisa), MEd (Unisa) verbonde aan die SAW Kollege vir Opvoedkundige Tegnologie se Navorsing en Ontwikkelingsvleuel.
}

\section{BIBLIOGRAFIE}

\section{BOEKE}

Baynes, J. (1987) Morale. A Study of Men and Courage. Heruitreiking. London: Leo Cooper.

Collins, A.S. (1980) Common Sense Training. San Rafael: Presidio Press

De Munnik, E.0. (1977) Die toepassing van Aktiwiteit as Didaktiese Beginsel in Militêre Opleiding. Pretoria: Universiteit van Suid-Afrika (M Ed-verhandeling).

De Munnik, E.0. (1979) Didaktiese Model vir Formele Indiensopleiding in Militêre Milieu. Pretoria: Universiteit van Suid-Afrika (DEd-proetskrif).

Downey, J.C.T. (1977) Management in the Armed Forces. Bristol: McGraw Hill Book Co.

Ginzberg, E. (1975) Breakdown and Recovery. Heruitreiking. Connecticut: Greenwood Press.

Hackett, J. (1983) The Profession of Arms. London: Sidgwick \& Jackson.

Hunter, E.J. (1982) Families under the Flag. New York: Praeger Publishers.

Janowitz, M. (1960) The Professional Soldier. Glencoe: The Free Press.

Van Dyk, P.S. (1980) Die Ontwikkeling van 'n Teoretiese Verwysingsraamwerk as Basis vir die Meting van Organisasiedoeltreffendheid in die SAW (Staandemag). Pretoria: Universiteit van Suid-Afrika. (M Comm-verhandeling).

Wool, H. (1968) The Military Specialist. Baltimore: John Hopkins Press.

VERSLAE

Hoof van die SAW (1987) Projek KINGSROW: Verslag oor die Ondersoek na 'n Stelsel vir die Ontwikkeling van Staandemagoffisiere in die SAW. (HSP/DBON/103/1/8/2/K345).

REFERATE

Van Niekerk, R. (1990) The Role of Educational Technology in Optimisation of Effective Adult Learning in the SADF. 